\title{
The Application of Linguistic Variation of Campus Catchwords in College English Teaching from the Perspective of Memetics
}

\author{
Qiao Zhang ${ }^{1, \text { a }}$, Ying $\mathrm{Wu}^{1}$ \\ ${ }^{1}$ Sichuan University of Media and Communications, Chengdu, Sichuan Province, China \\ a149180147@qq.com
}

Keywords: Memetics, Campus Catchword, College English Teaching.

\begin{abstract}
Based on Memetics, this paper analyzes the variation of the current situation on campus catchwords. It also describes the connotation and fun of catchwords in perspective of campus catchword memetics, as well as its popularity among the university students. Catchwords are mainly developed from the modern college students' personality. By observing the variation of catchwords, we summarize the rules of language development and evolution, which is helpful to provide new ideas of college English teaching and promote its level.
\end{abstract}

\section{Introduction}

Memetics is an important theory in language science. The term, meme, firstly appeared in Richard's work, The Selfish Gene. This term means some ideas or methods are inherited from generation to generation through the communication and record of human culture [1]. Meme is passed down due to human's communication and imitation. Language is an important carrier of human civilization. Meme is the summary of the rules of language development, which can promote the development of language and contribute to the communication and replication of language.

\section{Introduction of Memetics}

Foreign studies of Memetics have been lasting for a long time. There have been lots of systematic and scientific researches. And meme has been widely adopted in studies of sociology, psychology, culture and other fields, as well as the field of science. Domestic studies of Memetics are original from the paper named Memetics and Social Pragmatic [2]. The paper comprehensively elaborated the development of Memetics and the previous on it. By combining Chinese cultural features, it explores the phenomenon of meme of Chinese and the positive influences on language development. Since then, more and more scholars have carried out researches and explorations related to Memetics. However, domestic studies of Memetics have started later. Thus, it is still in the early stage.

Meme is based on linguistic imitation, and its center is imitation. A meme which is to be successful needs to go through four processes of assimilation, memory, expression and communication. Being an important theory in language culture, meme is of great positive significance on the development of language [3]. Memetics can expound the inherent rules of language development, which contributes to the preconditions of the language research and learning. In the language learning, Memetics proposes that the most important thing of language learning is copy and imitation, which is also an important channel for the students to learn a foreign language and obtain information. By summarizing the rules of language development, Memetics helps to promote the researches on language development and variation and provide a new way to learn. Language is the main carrier of memes and the essence of language is a meme. Therefore, in order to better explore the origin, development and variation of language, we apply Memetics to analyze language rules, which provides a new approach to study campus catchword variation.

Linguistic variation and change (LVC) is a new field of linguistic studies formed in 1960 [4]. Thus, more and more linguists have realized that variability is an important feature of language. Linguistic variation is mainly caused by the language, culture and social interaction between individuals. It is also an important research content in sociolinguistics. Variability is one of the fundamental features 
of language. Linguistic variation exists in every aspect of everyone's life, and the linguistic changes are persistent. The main purpose of linguistic variation and change is to create some kind of special, which gives people an impression of Foregrounding and draw people's attention and deepen their own memory. Some scholars propose that based on speakers' psychological requirements and cultural features, the transformation of general language is exactly language arts. The forms of linguistic change are devise, which can be reflected in language, aspect, as well as in vocabulary and grammar. These can reflect the speakers' rich cultural connotations.

\section{Campus Catchword Variation}

Linguistic variation is mainly caused by speakers' subjective intentions or environmental requirements, which is common in people's communication. In real life, speakers often use linguistic variation according to certain language standards. This kind of variation is actually the requirements of a friendly and easy-going communication. But in some special situations, speakers may need to damage these language standards to liven the atmosphere. It may lead to some unnatural feelings at the first time, but if speakers repeatedly use these irregular expressions over a period of time, people will gradually be used to this usage. Then the new expression has been formed. The language rules which are the feedback of meme are the same as that within the process [5].

The college students have just entered into the relaxed college life from rigorous sufferings in high school. Due to their mental immaturity, they tend to use peculiar language style in their daily communication. These frequently used words, sentences and grammar rules have become campus catchwords [6]. Being a new linguistic phenomenon, campus catchwords help the college students to express their individual characters and represent themselves. They also show the creation skills and publication ability of college students in language and vocabulary usage. Linguistic variation is not rare in social life. With the development of society, linguistic variation is now a common seen phenomenon in modern life. Variation is the normal state of language using, while campus catchwords is a form of Linguistic variation. Therefore, linguistic variation and changes happen on the basis of Memetics, which uses language as the carrier. Based on Memetics, this paper mainly analyzes that campus catchword variation can be used in college English teaching to improve the college English teaching.

\section{The Usage of Pronunciation Variation of Campus Catchwords in College English Teaching from the Perspective of Memetics}

The college students pursue personality publicity and self-presentation, and they like to use some simple expressions. Therefore, the expressions of homophones, numbers and letters have become popular campus language, which are widely used in their language learning.

\section{Homophones.}

Homophones refer to the expressions with similar or the same pronunciation but they have different meanings. They are characterized by the common usage at the same place in different situations. Therefore, they can add interestingness, creativity and freshness to campus catchwords. As the fruit of modern higher education, college students can be seen as pioneers of language innovation. They seek after individual characters and fashion trends. These phenomena can be found in the usage of campus catchwords. For example, "LOL (Laugh Out Loud)" can also refers to a popular network game "League of Legends" [7]; "IC" represents "I See"; "4 ever" stands for "Forever". These words are widely used in college students' daily communication. In college English teaching, these words can be used to improve their listening skills. Listening exercise is an important part in college English teaching. Applying these homophones in listening practice can help teachers to improve the enthusiasm of students, and impress them with listening materials.

\section{Syneresis.}

Syneresis refers to the reduction of vowels of the words. Being a form of campus catchword variation, it means that when the meaning of a word is clear and definite, some letters of this word can be cut off in specific circumstances. As another form of Linguistic variation, it is also commonly used 
in chatting and study of the college students. Such as cause (because), yep (yes), o (OK). Besides listening classes, these variations can also be found in America and Europe pop music. Students can learn the patterns of words variation through appreciation of European and American pop music. It also helps them to cultivate language sense, to deepen their understanding of English, and to stimulate their motivation of English learning.

\section{The Usage of Vocabulary Variation of Campus Catchwords in College English Teaching from the Perspective of Memetics}

Language reflects the level of social development, while the development and progress of a society also related to the development of language. In our cultural history, with the changes of dynasties and historical environments, new forms of expressions in culture and language appear in each historical period. This is well reflected in our traditional "verses, ditties, odes and songs -- the four forms of poetry". Vocabulary changing directly reflects the changes of cultural and social life in different periods. It is an important form of Linguistic variation, too. As an essential part of campus catchwords, vocabulary variation is also a kind of campus catchword variation, and can reflect the spirits and thoughts of contemporary college students.

\section{Acronym.}

Acronym refers to the English words that are composed of the first letter of the words in a phase. In their daily learning, college students often use acronym to shorten the time of spelling, in order to improve their study efficiency and information transmission rate. Such as "DIY (do it yourself)", "BF (boyfriend)", "BTW (by the way)". These abbreviations, though violated some rules of English grammar and spelling, belong to Linguistic variation. College students use them to make their communication more vivid and flexible. At the same time, they reflect the creativity of college students. This kind of psychological drive accelerate the spread and change of memes, and help college students to record information more conveniently.

\section{Innovative vocabulary.}

College students tend to pursue personality outspread, and like to use the new vocabulary with their own style. In campus life, college students create many new words which reflect the special objects and novel concepts in modern life. Through the creation of new words, their memory and understanding of these words deepened, their vocabulary expanded. College students evolve these words according to the basic meaning of these words, for example, "fat" - "fattism (prejudice against obese people)", "couch potato" - "mouse potato", "shopping" - "Showrooming (shopping first then buying online)".

\section{The Usage of Semantics Variation of Campus Catchwords in College English Teaching from the Perspective of Memetics}

The development of college students' personality promotes their desire to break the bondage of traditional expression. They are eager to find a new form of expression which is different from the common way. Semantic variation of campus catchwords is fresh and new way of language usage. In the process of college students' English learning, the grasp of accurate meaning is essential to understand the content of passage and effective expression. By mastering the meaning of campus catchwords after semantic variation, the students can improve their comprehension ability when reading articles.

Words with new meanings.

"Words with new meanings" means that, new meanings can be added to a word on the basis of invariant spelling. These meanings evolve from the word's original meaning. It is also an important form of Linguistic variation. After being endowed with new meanings, the word's spelling and pronunciation do not change, and its original connotation and usage still exist. For instance,

The word, alive, means lively and vivid originally. In the sentence of She is a girl alive to moods of others, alive means "sensitive". While in the sentence of The lake is alive with fish, alive means "very much" or "full of". 
The word, bubble, means foam. In the sentence of She came to the phone bubbling with excitement, it means keep speaking.

The word, mean, general refers to the "explain" or "refer to". But in the sentence of Don't be mean with fabric, otherwise curtains will end up looking skimpy, it refers stingy.

\section{Semantics distortion.}

Polysemy is a common phenomenon in English vocabulary. Through the features of a specific sentence and environment, a word with multiple meanings can express a certain kind of meaning. But listeners can distort speaker's original intention by the interpretation of polysemy. It is more widely used in talk show and humorous segments. This phenomenon can help students to deepen their understanding of vocabulary and improve their subjective initiative.

\section{Conclusions}

With Memetics, we summarize and analyze the variation of campus catchwords, which will deepen our understanding of the campus catchword variation and promote college English teaching.

\section{Acknowledgement}

This project, The Application of Linguistic Variation of Campus Catchwords in College English Teaching of Art Universities and Colleges from the Perspective of Memetics, is supported by Education Department of Sichuan Province (Project No.: 15SB0227).

\section{References}

[1] LI Shu-ying. Semantic Vagueness and Writing of CET 4 - A Study of the Influences of Semantic Vagueness on Internet Catchwords[J]. Journal of Higher Correspondence Education (Philosophy and Social Sciences), 2013, 12 (10): 88-90.

[2] QIAO Lei. On Morphological Forms and Prevalence Motivation of English Loanwords in Chinese [J]. JOURNAL OF YIBIN UNIVERSITY, 2013, 9 (5): 101-102.

[3] XIA Hong. Functional Grammar for Popular English Keywords in Network Chinese Utterance [J]. Journal of Shaoguan University, 2014, 16 (9): 122-125.

[4] BAO Wei. On the Popularity of English Words in Chinese from the Perspective of Memetics[J]. Journal of Lanzhou Institute of Technology, 2015, 22 (2): 109-111.

[5] LIU Wei-hong. A Study of the Top Buzzwords in English from the Perspective of Sociolinguistics [J]. Journal of Zhongyuan University of Technology, 2014, 25 (2): 30-34.

[6] ZHOU Yi-hong \& ZHAO Wen-jia. Research on the Influence of English Catchwords on the Visual-audio-oral Teaching of College English [J]. Anhui Literature, 2014, 21 (9): 152-153.

[7] WANG Li-song. The Formation and Development Tendency of Internet Catchwords from the Perspective of Memetics [J]. Crazy English Teachers, 2014, 16 (1): 160-163. 